\title{
Liquid-crystalline metallophthalocyanines containing late first-row transition metals
}

\author{
Jurgen Sleven, ${ }^{\mathrm{a}}$ Thomas Cardinaels, ${ }^{\mathrm{a}}$ Christiane Görller-Walrand, ${ }^{\mathrm{a}}$ and Koen Binnemans ${ }^{* \mathrm{a}}$ \\ ${ }^{a}$ Katholieke Universiteit Leuven, Department of Chemistry Celestijnenlaan 200F, B-3001 \\ Leuven, Belgium \\ E-mail: Koen.Binnemans@,chem.kuleuven.ac.be
}

\section{Dedicated to Professor Georges Hoornaert on his $65^{\text {th }}$ birthday}

(received 16 Nov 02; accepted 03 Mar 03; published on the web 14 Mar 03)

\begin{abstract}
Cobalt(II), nickel(II), copper(II) and zinc(II) phthalocyanines substituted by eight alkoxy chains in the peripheral $(2,3,9,10,16,17,23,24)$ positions were prepared. The alkoxy chain lengths are octyloxy $\left(\mathrm{C}_{8} \mathrm{H}_{17} \mathrm{O}\right)$, dodecyloxy $\left(\mathrm{C}_{12} \mathrm{H}_{25} \mathrm{O}\right)$ and hexadecyloxy $\left(\mathrm{C}_{16} \mathrm{H}_{33} \mathrm{O}\right)$. Studies by polarized optical microscopy and high-temperature $\mathrm{X}$-ray diffraction revealed that all the complexes are liquid-crystalline and that they exhibit a hexagonal columnar mesophase $\left(\mathrm{Col}_{h}\right)$. Transition enthalpies were determined by differential scanning calorimetry (DSC). The clearing point could only be observed for the compounds with the hexadecyloxy chains. The melting points depend on the central metal ion: $\mathrm{Ni}^{\mathrm{II}}<\mathrm{Cu}^{\mathrm{II}} \approx \mathrm{Co}^{\mathrm{II}}<\mathrm{Zn}^{\mathrm{II}}$. The clearing point could only be observed for the compounds with the hexadecyloxy chains, and it was found that the nature of the metal ion has negligible influence on the clearing point.
\end{abstract}

Keywords: Liquid crystals, macrocycles, metallomesogens, phthalocyanines, transition metals

\section{Introduction}

The ability of phthalocyanines to form liquid-crystalline phases was first demonstrated by Piechocki et al. for the peripherally octakis(dodecyloxymethyl) substituted copper(II) phthalocyanine. ${ }^{1}$ This compound exhibits a disordered hexagonal columnar mesophase over a wide temperature range (from $53{ }^{\circ} \mathrm{C}$ to more than $300{ }^{\circ} \mathrm{C}$ ). Since this pioneering work many different liquid-crystalline phthalocyanines have been prepared with the aim to explore the influence of parameters such as the number of side chains, the length of the side chains, branching of the chains and the type of linking group (alkoxy, alkyl, alkoxymethyl, ...). Much less attention was paid to the influence of the central metal ion on the mesophase stability 
range. ${ }^{2-5}$ For the metallophthalocyanines with eight peripheral alkoxymethyl chains, the melting point increases in the order $\mathrm{Pb}^{\mathrm{II}}<\mathrm{Mn}^{\mathrm{II}}<\mathrm{Cu}^{\mathrm{II}}<\mathrm{Sn}^{\mathrm{IV}}(\mathrm{OH})_{2}<\mathrm{Zn}^{\mathrm{II}} \approx \mathrm{H}_{2}$, whereas the clearing point increases in the order $\mathrm{Sn}^{\text {IV }}(\mathrm{OH})_{2}<\mathrm{Pb}^{\text {II }}<\mathrm{H}_{2}<\mathrm{Mn}^{\text {II }}<\mathrm{Cu}^{\text {II }} \approx \mathrm{Zn}^{\text {II }} .{ }^{1,2,6}$ Here, it should be noted that the lead(II) and tin(IV)dihydroxide ions are too large to fit in the central cavity of the phthalocyanine ring. ${ }^{7,8}$ For the metallophthalocyanines substituted by eight peripherally alkoxy chains, trends in the reported data of the transitions temperatures are much less clear. Severs et $a l .{ }^{9}$ describe the thermal behaviour of metallophthalocyanines with eight peripheral dodecyloxy chains and with $\mathrm{Co}^{\mathrm{II}}, \mathrm{Ni}^{\mathrm{II}}, \mathrm{Cu}^{\mathrm{II}}$ and $\mathrm{Zn}^{\mathrm{II}}$ as the central metal ion. However, in this paper the mesophase is not identified (only labeled as 'discotic'), and some of thermal data in this paper give rise to questions. For instance, according to these authors, the mesophase range of the nickel(II) compound is about $100{ }^{\circ} \mathrm{C}$ less than that of the corresponding cobalt(II) compound. Their findings differ from those of an earlier reported copper(II) phthalocyanine compound too. ${ }^{10,11}$

In this paper, we report on the influence of the central metal ion $\left(\mathrm{M}=\mathrm{Co}^{\mathrm{II}}, \mathrm{Ni}^{\mathrm{II}}, \mathrm{Cu}^{\mathrm{II}}, \mathrm{Zn}^{\mathrm{II}}\right)$ on the transition temperatures of metallophthalocyanines with eight peripheral alkoxy chains (Figure 1). The aim of the study was to compare the thermal data with those obtained for other liquid-crystalline phthalocyanines, in order to establish some general rules, and to solve discrepancies in earlier literature reports on similar compounds. This study is a continuation of our earlier work on liquid-crystalline metallophthalocyanines. ${ }^{12-14}$ 


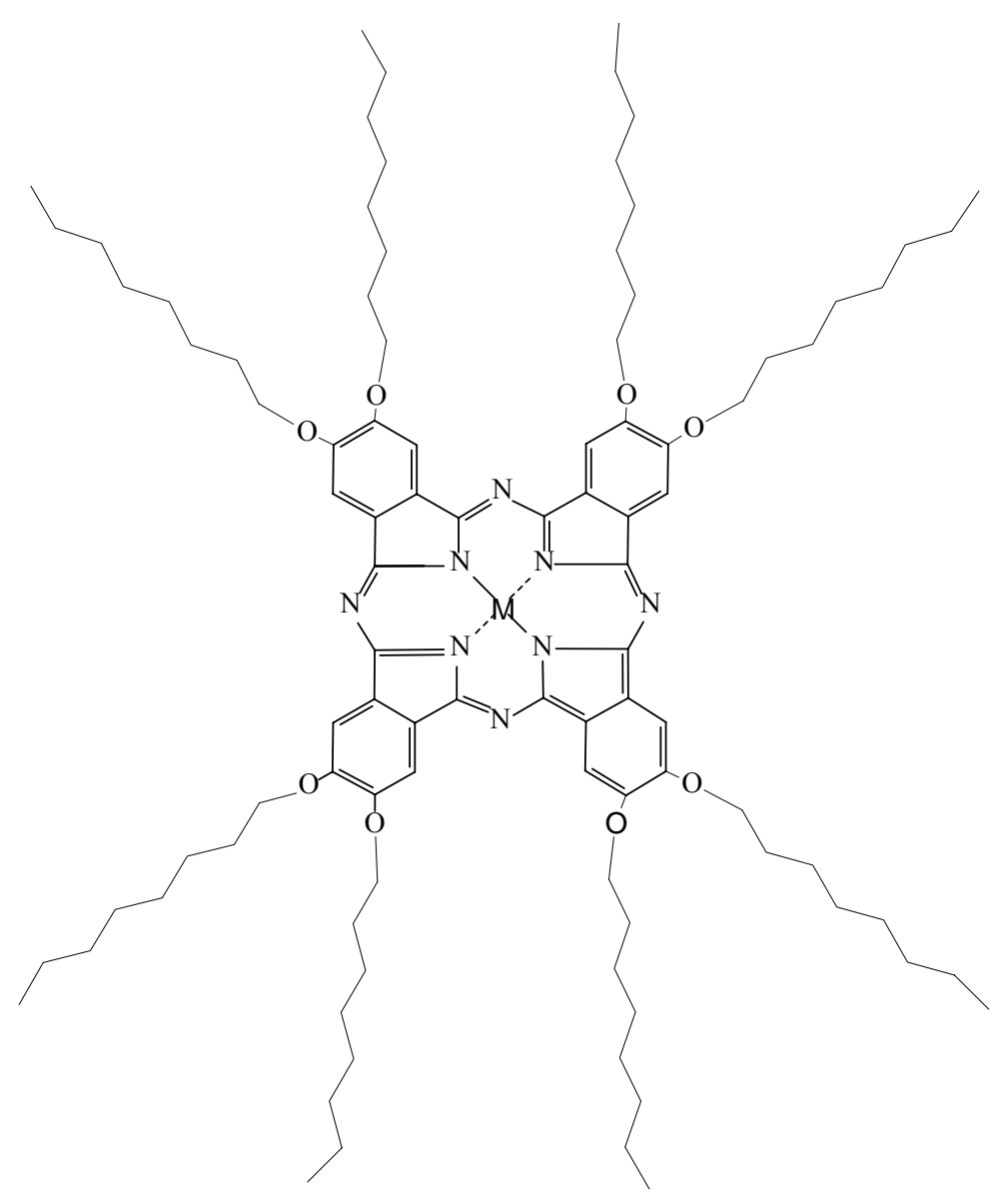

Figure 1. Structure of an octakis(octyloxy) substituted phthalocyanine transition metal(II) complex $\left(\mathrm{M}=\mathrm{Co}^{\mathrm{II}}, \mathrm{Ni}^{\mathrm{II}}, \mathrm{Cu}^{\mathrm{II}}, \mathrm{Zn}^{\mathrm{II}}\right)$.

\section{Results and Discussion}

The transition metal complexes were prepared by the template reaction of four phthalonitrile precursors with a metal ion (scheme 1). The phthalonitriles were prepared via a three stepreaction, consisting of alkylation of catechol via a Williamson etherification reaction, secondly dibromination of the 1,2-dialkoxybenzenes and finally substitution of the bromine atoms by cyano groups via a Rosenmund-Von Braun reaction. ${ }^{10,12}$ The template reaction consists of a reaction of the phthalonitrile with $1 / 4$ equivalent transition metal chloride salt in the presence of $1 / 2$ equivalent of DBU in 2-(dimethylamino)ethanol. After a reaction time of 48 hours, the mixture was dissolved in a minimum amount of chloroform and the product was precipitated in acetone and filtered. Further purification was done by column chromatography over neutral alumina (eluent: $\mathrm{CHCl}_{3}$ ) and recrystallization in ethyl acetate. Table 1 gives an overview of the octa-alkyloxy substituted phthalocyanine transition metal complexes that were synthesized. The elemental analysis did not always yield satisfying results but this is usual for this type of 
compounds due to the formation of refractory materials during the combustion. The metal complexes were identified by MALDI-TOF mass spectrometry. Although the metal-free phthalocyanine is the main impurity formed during the template reaction, both MALDI-TOF and UV/VIS spectra showed that the purified metallophthalocyanines are free from $\mathrm{PcH}_{2}$ impurities. Purity control can be done by UV/VIS spectroscopy, because the spectrum of the metallophthalocyanine is markedly different from the spectrum of the corresponding metal-free phthalocyanine (different splitting of the Q-band).<smiles>[R20]c1cc(C#N)c(C#N)cc1[R20]</smiles>

$$
\begin{gathered}
+1 / 4 \mathrm{MCl}_{2} \cdot \mathrm{xH}_{2} \mathrm{O} \quad \underset{\mathrm{DMAE}}{\stackrel{\mathrm{DBU}}{\longrightarrow}} \\
\mathrm{R}=\mathrm{C}_{8} \mathrm{H}_{17}, \mathrm{C}_{12} \mathrm{H}_{25}, \mathrm{C}_{16} \mathrm{H}_{33} \\
\mathrm{M}=\mathrm{Ni}, \mathrm{Co}, \mathrm{Cu}, \mathrm{Zn}
\end{gathered}
$$

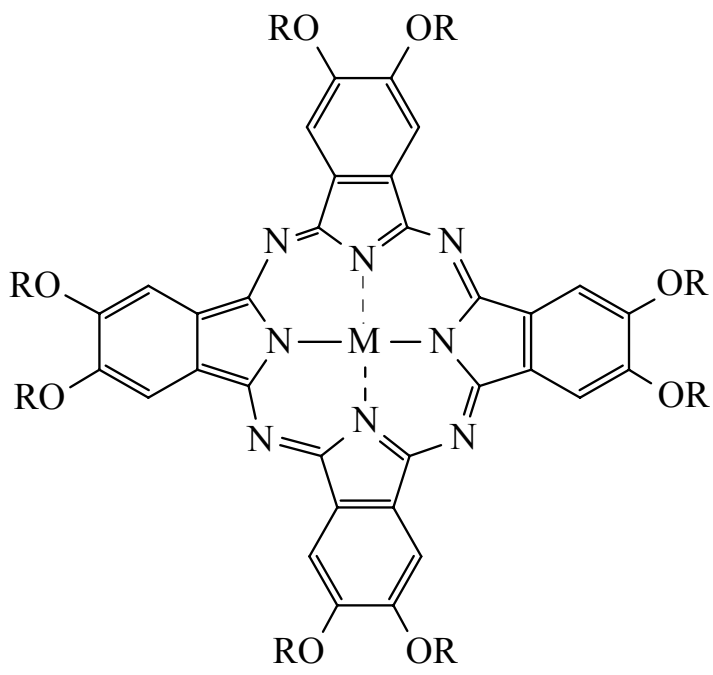

\section{Scheme 1}

Table 1. MALDI-TOF data of the octakis(alkoxy)-substituted metallophthalocyanines

\begin{tabular}{llll}
\hline Compound & Formula & M (isotopic) & M (found) \\
\hline$\left(\mathrm{C}_{8} \mathrm{H}_{17} \mathrm{O}\right)_{8} \mathrm{PcZn}$ & $\mathrm{C}_{96} \mathrm{H}_{144} \mathrm{O}_{8} \mathrm{~N}_{8} \mathrm{Zn}$ & 1601.04 & 1602.2 \\
$\left(\mathrm{C}_{8} \mathrm{H}_{17} \mathrm{O}\right)_{8} \mathrm{PcCu}$ & $\mathrm{C}_{96} \mathrm{H}_{144} \mathrm{O}_{8} \mathrm{~N}_{8} \mathrm{Cu}$ & 1600.04 & 1599.7 \\
$\left(\mathrm{C}_{8} \mathrm{H}_{17} \mathrm{O}\right)_{8} \mathrm{PcNi}$ & $\mathrm{C}_{96} \mathrm{H}_{144} \mathrm{O}_{8} \mathrm{~N}_{8} \mathrm{Ni}$ & 1595.05 & 1596.1 \\
$\left(\mathrm{C}_{8} \mathrm{H}_{17} \mathrm{O}\right)_{8} \mathrm{PcCo}$ & $\mathrm{C}_{96} \mathrm{H}_{144} \mathrm{O}_{8} \mathrm{~N}_{8} \mathrm{Co}$ & 1596.04 & 1596.0 \\
$\left(\mathrm{C}_{12} \mathrm{H}_{25} \mathrm{O}\right)_{8} \mathrm{PcZn}$ & $\mathrm{C}_{128} \mathrm{H}_{208} \mathrm{O}_{8} \mathrm{~N}_{8} \mathrm{Zn}$ & 2049.54 & 2050.8 \\
$\left(\mathrm{C}_{12} \mathrm{H}_{25} \mathrm{O}\right)_{8} \mathrm{PcCu}$ & $\mathrm{C}_{128} \mathrm{H}_{208} \mathrm{O}_{8} \mathrm{~N}_{8} \mathrm{Cu}$ & 2048.54 & 2049.0 \\
$\left(\mathrm{C}_{12} \mathrm{H}_{25} \mathrm{O}\right)_{8} \mathrm{PcNi}$ & $\mathrm{C}_{128} \mathrm{H}_{208} \mathrm{O}_{8} \mathrm{~N}_{8} \mathrm{Ni}$ & 2043.55 & 2043.6 \\
$\left(\mathrm{C}_{12} \mathrm{H}_{25} \mathrm{O}\right)_{8} \mathrm{PcCo}$ & $\mathrm{C}_{128} \mathrm{H}_{208} \mathrm{O}_{8} \mathrm{~N}_{8} \mathrm{Co}$ & 2044.54 & 2043.6 \\
$\left(\mathrm{C}_{16} \mathrm{H}_{33} \mathrm{O}\right)_{8} \mathrm{PcZn}$ & $\mathrm{C}_{160} \mathrm{H}_{272} \mathrm{O}_{8} \mathrm{~N}_{8} \mathrm{Zn}$ & 2498.04 & 2496.9 \\
$\left(\mathrm{C}_{16} \mathrm{H}_{33} \mathrm{O}\right)_{8} \mathrm{PcCu}$ & $\mathrm{C}_{160} \mathrm{H}_{272} \mathrm{O}_{8} \mathrm{~N}_{8} \mathrm{Cu}$ & 2497.04 & 2497.2 \\
$\left(\mathrm{C}_{16} \mathrm{H}_{33} \mathrm{O}\right)_{8} \mathrm{PcNi}$ & $\mathrm{C}_{160} \mathrm{H}_{272} \mathrm{O}_{8} \mathrm{~N}_{8} \mathrm{Ni}$ & 2492.05 & 2490.7 \\
$\left(\mathrm{C}_{16} \mathrm{H}_{33} \mathrm{O}\right)_{8} \mathrm{PcCo}$ & $\mathrm{C}_{160} \mathrm{H}_{272} \mathrm{O}_{8} \mathrm{~N}_{8} \mathrm{Co}$ & 2493.04 & 2492.0 \\
\hline
\end{tabular}


Molecules of peripherally octa-alkoxy phthalocyanines have been reported to stack one above another to columns that are ordered in a hexagonal two-dimensional lattice, thus forming a hexagonal columnar mesophases $\left(\mathrm{Col}_{h}\right)$. The mesomorphic properties of the compounds were determined by hot stage polarizing optical microscopy, differential scanning calorimetry (DSC) and high temperature X-ray measurements. In order to obtain data that can be compared with one another, all complexes were measured by DSC in the same way. First the sample was heated from $0{ }^{\circ} \mathrm{C}$ into the mesophase, after this the sample was cooled again to $0{ }^{\circ} \mathrm{C}$ and heated up to $350{ }^{\circ} \mathrm{C}$ in order to determine the clearing point. All measured complexes were liquid-crystalline. The viscosity of the mesophase is quite high, but decreases gradually with increasing temperatures. It is easier to detect the melting point by DSC then by optical microscopy, but optical microscopy had to be used to discriminate between a crystal-to-crystal transition and the melting point. Figure 2 shows a DSC thermogram for the octakishexadecyloxy zinc(II) phthalocyanines. The DSC thermograms of the other ligands were similar to this one. The first peak in the thermogram is a crystal-crystal transition, the second peak is the solid-to-mesophase transition peak (melting point). The sharpness of the melting point gives an indication on the purity of the compound. The surface under the peaks is a measure for the transition enthalpy $\Delta H$. The clearing point enthalpy is much smaller than the melting enthalpy, which is due to the fact that for the mesophase to isotropic transition the structural rearrangement of the molecules is far more relevant than for the solid to mesophase transition. The mosaic texture observed by polarized optical microscopy with crossed polarizers is typical that of a hexagonal columnar mesophase. The best textures where observed when the mesophase was obtained by cooling from the isotropic liquid. The texture observed upon heating the solid compound is much less typical, although after annealing a mosaic-like texture was formed (Figure 3). The texture observed between parallel polarizers is that of so-called 'digitate stars'. ${ }^{11}$ Table 2 gives an overview of the thermodynamic properties of the phthalocyanine transition metal complexes we synthesized. 


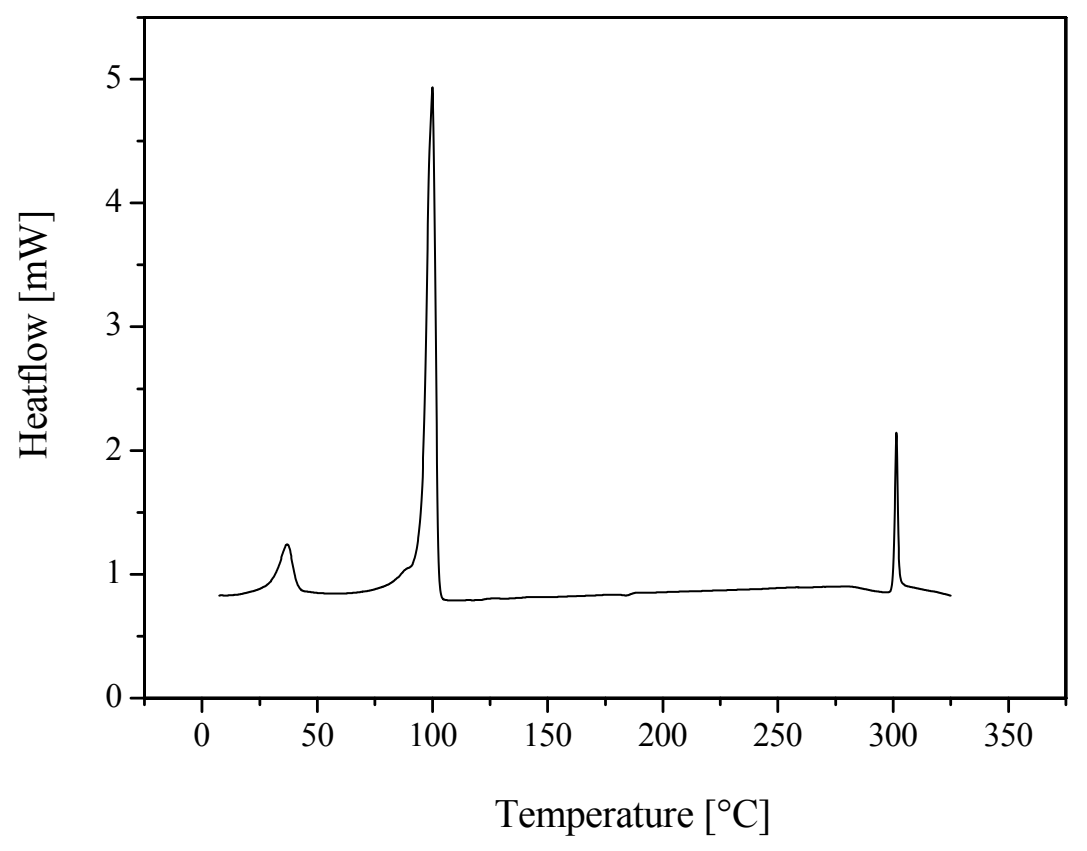

Figure 2. DSC thermogram of the octakis(hexadecyloxy)phthalocyaninato zinc(II) complex.

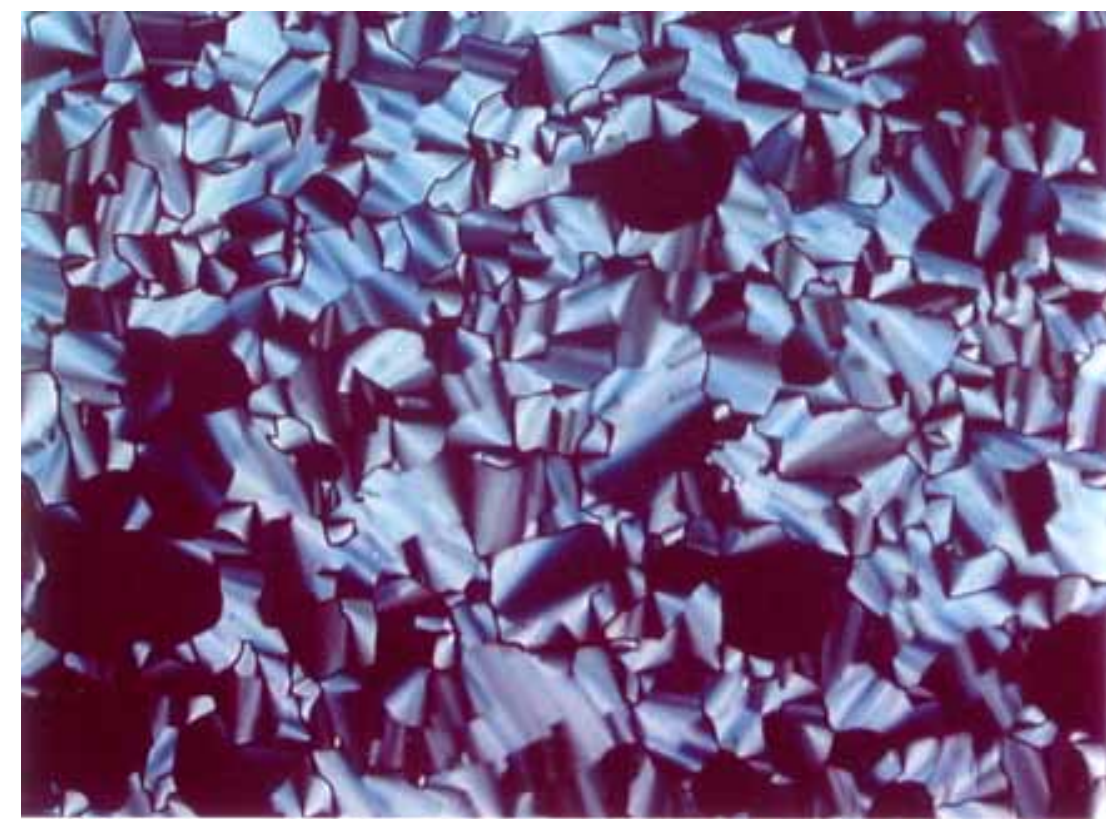

Figure 3. Texture of $\left(\mathrm{C}_{16} \mathrm{H}_{33} \mathrm{O}\right)_{8} \mathrm{PcCo}$ between crossed polarizers in the hexagonal columnar mesophase.

Table 2. Mesophase behavior of the octakis(alkoxy)-substituted metallophthalocyanine complexes. All the compounds exhibit a hexagonal columnar mesophase $\left(\mathrm{Col}_{\mathrm{h}}\right)^{*}$ 


\begin{tabular}{lcccc}
\hline & $T_{m}\left({ }^{\circ} \mathrm{C}\right)$ & $\Delta H_{m}\left(\mathrm{~kJ} \mathrm{~mol}^{-1}\right)$ & $T_{c}\left({ }^{\circ} \mathrm{C}\right)$ & $\Delta H_{c}\left(\mathrm{~kJ} \mathrm{~mol}^{-1}\right)$ \\
\hline$\left(\mathrm{C}_{8} \mathrm{H}_{17} \mathrm{O}\right)_{8} \mathrm{PcZn}$ & 135 & 102 & $\mathrm{Dec}^{* *}$ & --- \\
$\left(\mathrm{C}_{8} \mathrm{H}_{17} \mathrm{O}\right)_{8} \mathrm{PcCu}$ & 123 & 83 & Dec & --- \\
$\left(\mathrm{C}_{8} \mathrm{H}_{17} \mathrm{O}\right)_{8} \mathrm{PcNi}$ & 110 & 66 & $\mathrm{Dec}$ & --- \\
$\left(\mathrm{C}_{8} \mathrm{H}_{17} \mathrm{O}\right)_{8} \mathrm{PcCo}$ & 123 & 68 & $\mathrm{Dec}$ & --- \\
$\left(\mathrm{C}_{12} \mathrm{H}_{25} \mathrm{O}\right)_{8} \mathrm{PcZn}$ & 111 & 106 & $\mathrm{Dec}$ & --- \\
$\left(\mathrm{C}_{12} \mathrm{H}_{25} \mathrm{O}\right)_{8} \mathrm{PcCu}$ & 101 & 97 & $\mathrm{Dec}$ & --- \\
$\left(\mathrm{C}_{12} \mathrm{H}_{25} \mathrm{O}\right)_{8} \mathrm{PcNi}$ & 83 & 84 & Dec & --- \\
$\left(\mathrm{C}_{12} \mathrm{H}_{25} \mathrm{O}\right)_{8} \mathrm{PcCo}$ & 101 & 103 & Dec & --- \\
$\left(\mathrm{C}_{16} \mathrm{H}_{33} \mathrm{O}\right)_{8} \mathrm{PcZn}$ & 100 & 149 & 301 & 14 \\
$\left(\mathrm{C}_{16} \mathrm{H}_{33} \mathrm{O}\right)_{8} \mathrm{PcCu}$ & 93 & 125 & 300 & 12 \\
$\left(\mathrm{C}_{16} \mathrm{H}_{33} \mathrm{O}\right)_{8} \mathrm{PcNi}$ & 49 & 106 & 296 & 11 \\
$\left(\mathrm{C}_{16} \mathrm{H}_{33} \mathrm{O}\right)_{8} \mathrm{PcCo}$ & 92 & 61 & 306 & 10 \\
\hline
\end{tabular}

*The melting point $\left(\mathrm{T}_{\mathrm{m}}\right)$ and clearing points $\left(\mathrm{T}_{\mathrm{c}}\right)$ have been determined by differential scanning calorimetry. The reported temperatures are peak temperatures.

** Dec $=$ decomposition above $350^{\circ} \mathrm{C}$.

Figure 4 shows graphically the influence of the central metal ion on the transition temperatures of the octakis(hexadecyloxy) compounds. The compounds have a large thermal range of the mesophase, extending over a range of more than $250^{\circ} \mathrm{C}$. This high stability can be attributed to the strong van der Waals interactions between the alkyl chain and to the $\pi-\pi$ interactions between the phthalocyanine cores. The clearing point could only be observed for the compounds with the hexadecyloxy chains. The melting points depend on the central metal ion: $\mathrm{Ni}^{\mathrm{II}}<\mathrm{Cu}^{\mathrm{II}} \approx \mathrm{Co}^{\mathrm{II}}<\mathrm{Zn}^{\mathrm{II}}$. The clearing point could only be observed for the compounds with the hexadecyloxy chains, and it was found that the nature of the metal ion has a negligible influence on this transition. Longer alkoxy chains tend to lower the transition temperatures of the compounds. The melting points of these metallophthalocyanines are in general higher than that of the corresponding metal-free phthalocyanines. However the melting points of the metal-free phthalocyanine are very comparable with those of the nickel(II) phthalocyanine. In contrast to earlier work by Severs et al. ${ }^{9}$ where these authors find scattered values for the transition temperatures, the trends we observe are much smoother. In this respect, our results are in better agreement with those reported by Van der Pol et al. ${ }^{10,11}$ for the copper(II) phthalocyanines (especially the fact that the compounds with the shorter chain lengths decompose before the clearing point is being reached). 


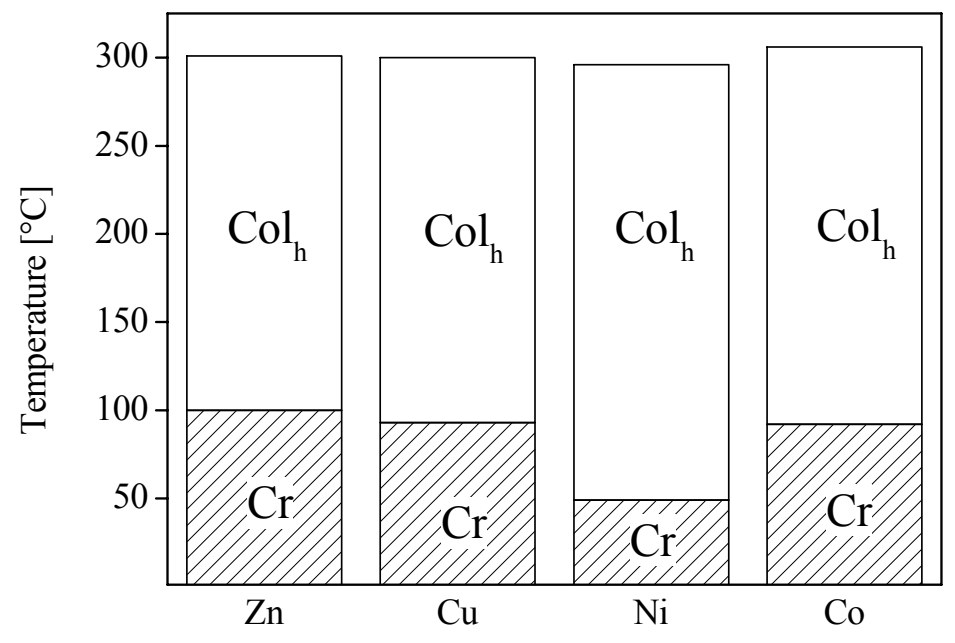

Figure 4. Influence of the central metal ion on the transition temperatures of the octakis(hexadecyloxy) metallophthalocyanine complexes.

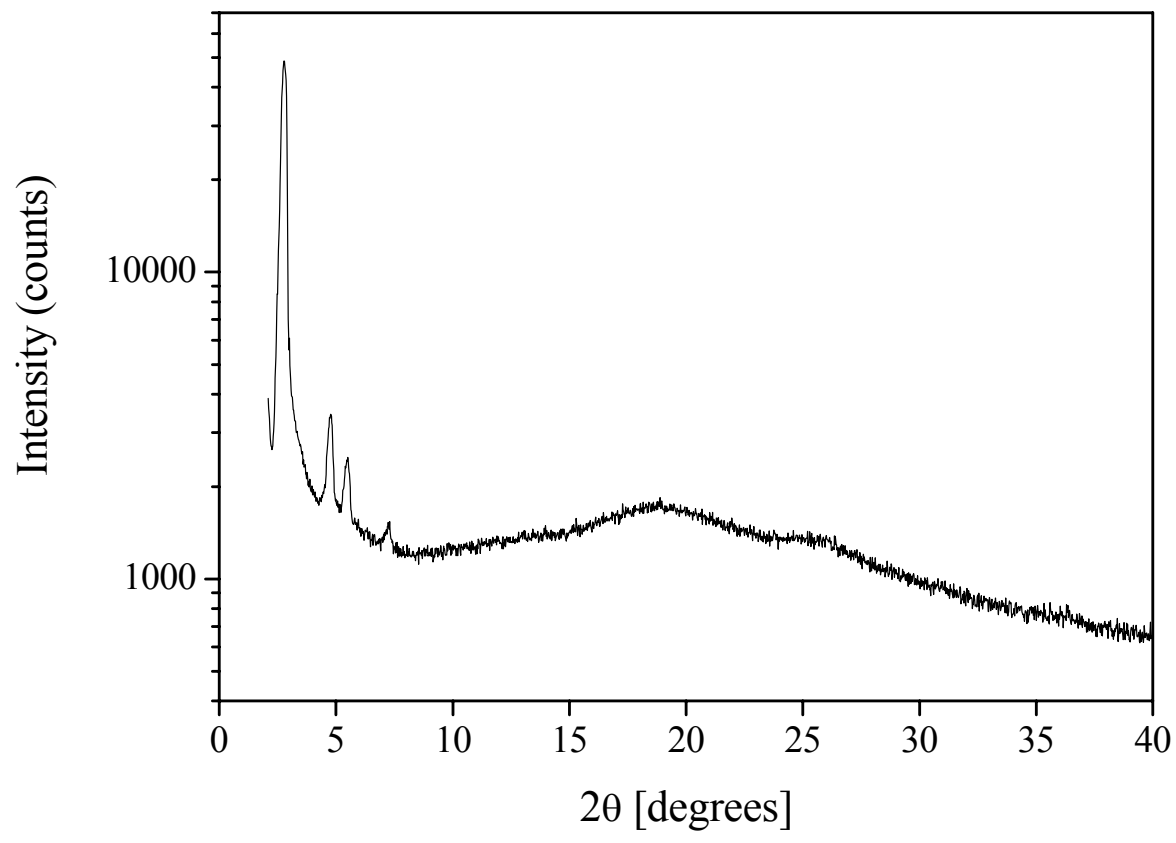

Figure 5. High-temperature X-ray diffractogram of the octakis(hexadecyloxy)phthalocyaninato zinc(II) complex.

High temperature X-ray diffraction experiments measurements confirmed the presence of a two-dimensional hexagonal lattice. Figure 5 shows the diffractogram of octakishexadecyloxy 
phthalocyanine zinc(II) complex at $120{ }^{\circ} \mathrm{C}$. Four Bragg reflections having reciprocal spacings of $1: \sqrt{3}: \sqrt{4}: \sqrt{7}$ were observed. This is characteristic for a two-dimensional hexagonal lattice as in the columnar mesophase. A broad peak at a wider angle $\left(2 \theta=19^{\circ}\right)$ could also be observed. This peak corresponds to the long aliphatic chains that are located randomly within the columnar mesophase with an average spacing of $4.6 \AA$. A less broad peak was found round $3.4 \AA$, which is the stacking distance of the phthalocyanine cores within the columns. These results are similar to the data of the dodecyloxy-substituted phthalocyanines obtained by Ohta et al., ${ }^{15}$ and by van der Pol et al.. ${ }^{10,11}$ Strictly speaking, a distinction can be made between an ordered and a disordered hexagonal columnar mesophase (and in our case we have ordering along the columns), we prefer to label our mesophase as a hexagonal columnar mesophase only.

Spectroscopic measurements (optical absorption spectra and MCD spectra) were made to investigate the influence of the central metal ion on the position of the spectral bands. Table 3 lists the peak positions and molar absorptivities of the Q-band of the synthesized complexes. Figure 6 shows the absorption spectrum for the metal free octakishexadecyloxy phthalocyanine (left) and for the octakishexadecyloxy phthalocyanine zinc complex (right), in chloroform. For the metal free phthalocyanine all states are non-degenerate $\left(\mathrm{D}_{2 \mathrm{~h}}\right)$ and the $\mathrm{Q}$-band is split in a $\mathrm{Q}_{\mathrm{x}}$ and a $\mathrm{Q}_{\mathrm{y}}$ peak as shown in the spectrum. For the metal complex this split is no longer present since the excited state of the Q-band is degenerate. This is emphasized in the MCD spectra of the complex and the ligand. For the complex an A-term is centered on the maximum of the Qabsorption peak. Figure 7 shows the MCD spectra for the octakisdodecyloxy phthalocyanine ligand and copper complex respectively.

The chain length has hardly any influence on the position and wavenumber of the Q-band. However, the Q-band is more intense for the copper(II) phthalocyanines than for the other metallophthalocyanines. The lowest intensity is observed for the cobalt(II) phthalocyanines, but the position of the zinc(II) and nickel(II) complex is more difficult to establish. The Q-band was found to shift to the red in the order $\mathrm{Co}^{\mathrm{II}} \approx \mathrm{Ni}^{\mathrm{II}}<\mathrm{Zn}^{\mathrm{II}}<\mathrm{Cu}^{\mathrm{II}}$. The total shift between the cobalt(II) and the copper(II) phthalocyanines is about $10 \mathrm{~nm}$. After standing for several days, the blue green solutions of the zinc(II) phthalocyanines turned yellow. The reason for this behavior is that phthalocyanines containing diamagnetic metal ions, efficiently generate singlet-oxygen. This species has a bleaching action. 

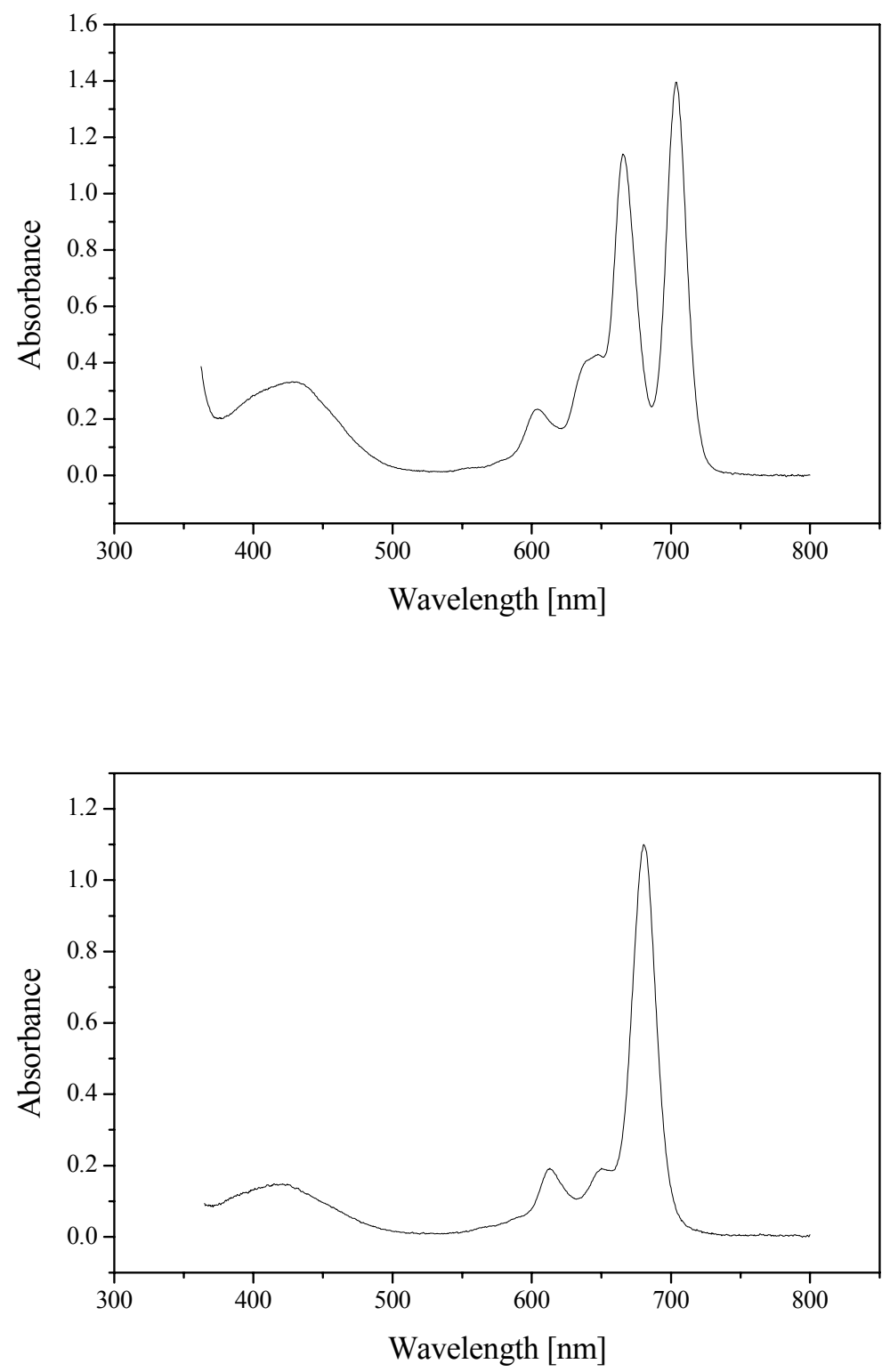

Figure 6. Absorption spectrum in chloroform for the metal free octakis(dodecyloxy) phthalocyanine (top) and for the octakis(dodecyloxy)phthalocyaninato copper (II) complex (bottom). 

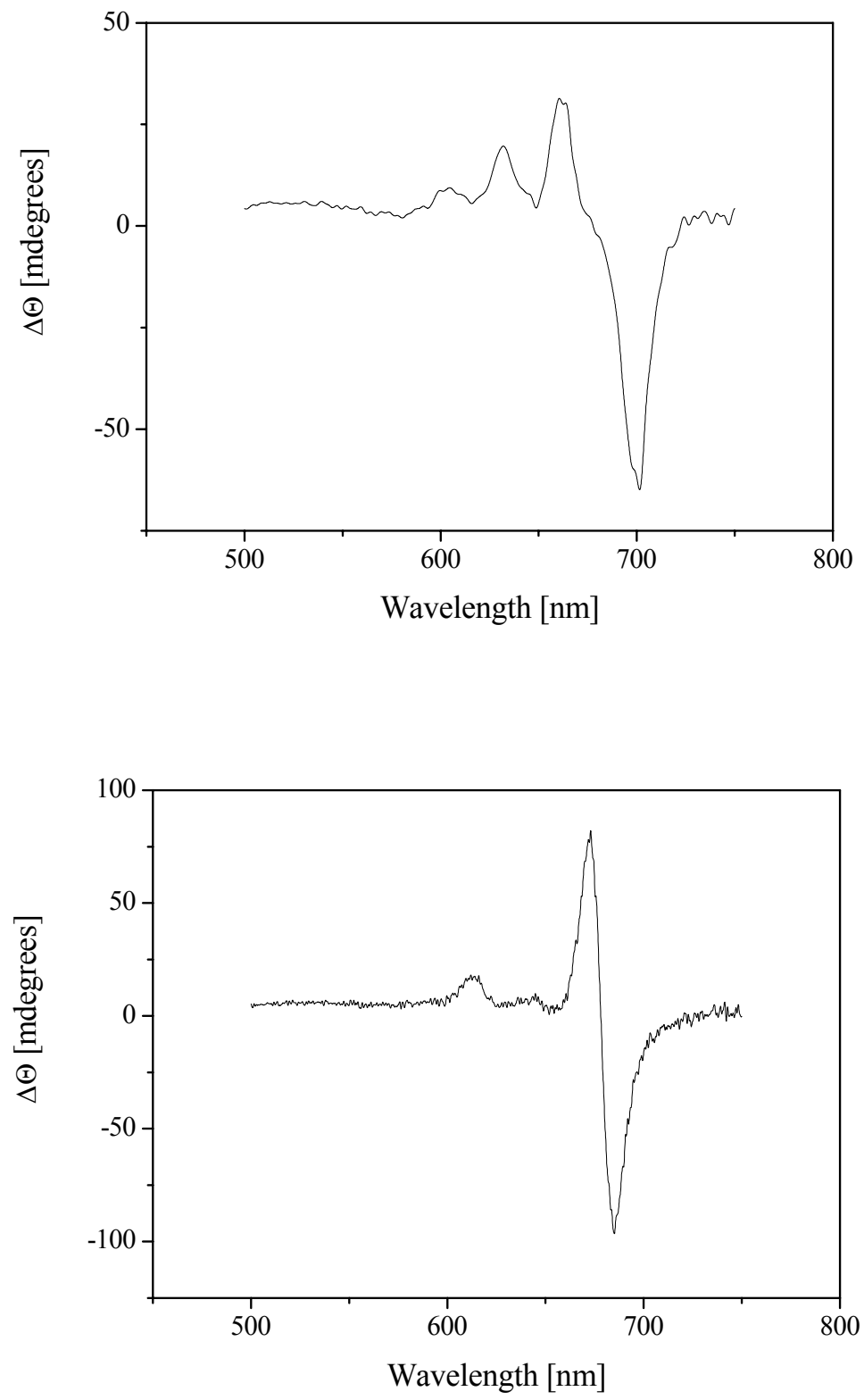

Figure 7. MCD spectrum in chloroform for the metal free octakis(dodecyloxy) phthalocyanine (top) and for the octakis(dodecyloxy)phthalocyaninato copper (II) complex (bottom).

Table 3. Q-band absorption maxima octakis(alkoxy)-substituted metallophthalocyanine complexes

\begin{tabular}{ccc}
\hline Compound & $\log \varepsilon$ & $\lambda_{\max }(\mathrm{nm})$ \\
\hline$\left(\mathrm{C}_{8} \mathrm{H}_{17} \mathrm{O}\right)_{8} \mathrm{PcZn}$ & 5.19 & 679.0
\end{tabular}




\begin{tabular}{lll}
$\left(\mathrm{C}_{8} \mathrm{H}_{17} \mathrm{O}\right)_{8} \mathrm{PcCu}$ & 5.29 & 681.5 \\
$\left(\mathrm{C}_{8} \mathrm{H}_{17} \mathrm{O}\right)_{8} \mathrm{PcNi}$ & 5.25 & 672.5 \\
$\left(\mathrm{C}_{8} \mathrm{H}_{17} \mathrm{O}\right)_{8} \mathrm{PcCo}$ & 5.01 & 672.0 \\
$\left(\mathrm{C}_{12} \mathrm{H}_{25} \mathrm{O}\right)_{8} \mathrm{PcZn}$ & 5.18 & 679.0 \\
$\left(\mathrm{C}_{12} \mathrm{H}_{25} \mathrm{O}\right)_{8} \mathrm{PcCu}$ & 5.34 & 681.5 \\
$\left(\mathrm{C}_{12} \mathrm{H}_{25} \mathrm{O}\right)_{8} \mathrm{PcNi}$ & 5.24 & 673.0 \\
$\left(\mathrm{C}_{12} \mathrm{H}_{25} \mathrm{O}\right)_{8} \mathrm{PcCo}$ & 5.10 & 672.0 \\
$\left(\mathrm{C}_{16} \mathrm{H}_{33} \mathrm{O}\right)_{8} \mathrm{PcZn}$ & 5.16 & 680.5 \\
$\left(\mathrm{C}_{16} \mathrm{H}_{33} \mathrm{O}\right)_{8} \mathrm{PcCu}$ & 5.28 & 681.5 \\
$\left(\mathrm{C}_{16} \mathrm{H}_{33} \mathrm{O}\right)_{8} \mathrm{PcNi}$ & 5.10 & 672.5 \\
$\left(\mathrm{C}_{16} \mathrm{H}_{33} \mathrm{O}\right)_{8} \mathrm{PcCo}$ & 5.01 & 672.0 \\
\hline
\end{tabular}

\section{Conclusions}

Cobalt(II), nickel(II), copper(II) and zinc(II) phthalocyanines substituted with eight alkoxy chains in the peripheral $(2,3,9,10,16,17,23,24)$ positions were prepared. All the compounds exhibit a hexagonal columnar mesophase over a wide temperature range $\left(>250{ }^{\circ} \mathrm{C}\right)$. The transition temperatures decrease with increasing chain length. Independent of the chain length, the melting points increase in the order $\mathrm{Ni}^{\mathrm{II}}<\mathrm{Cu}^{\mathrm{II}} \approx \mathrm{Co}^{\mathrm{II}}<\mathrm{Zn}^{\mathrm{II}}$ and are higher than that of the corresponding metal-free phthalocyanine. The clearing points could only be observed for compounds with long alkyl chains $\left(\mathrm{C}_{16} \mathrm{H}_{33} \mathrm{O}\right)$, because the other compounds start to decompose before clearing. The clearing points do not depend on the metal ion. Such clear trends have not been observed in the past for similar metallophthalocyanine complexes.

\section{Experimental Section}

General Procedures. All ${ }^{1} \mathrm{H}$ NMR spectra were recorded on a Bruker Avance 300 spectrometer (300 MHz) using $\mathrm{CDCl}_{3}$ as solvent and tetramethylsilane (TMS) as internal standard. Elemental analyses $(\mathrm{CHN})$ were performed on a CE-Instrument EA-1110 elemental analyzer. Mass spectra 
of the organic precursors were recorded on a low resolution electron-impact Hewlett-Packard 5989A for low molecular mass substances. For the phthalocyanines a Micromass Quattro II (triple quadrupole) was used. MALDI-TOF mass spectra of the cobalt(II) complexes were measured on a VG Tofspec SE (Micromass, UK) equipped with a $\mathrm{N}_{2}$-laser (337 nm). Column chromatography was done over ICN 63-200 (60 A) Silica gel and Merck 90 active neutral Alumina UV-Vis spectra were measured on a Shimadzu UV-3100 spectrophotometer, with spectrograde chloroform as the solvent. MCD spectra were recorded on an AVIV 62 DS CD-spectrometer, extended with an electromagnet (1 Tesla). IR spectra have been obtained on a Bruker IFS66 FTIR-spectrometer. The KBr-pellet technique was used to measure the samples. Differential scanning calorimetry (DSC) measurements were made on a Mettler-Toledo DSC 821e module (scan rate $10{ }^{\circ} \mathrm{C} \mathrm{min}^{-1}$ under a nitrogen flow, aluminum cups). Optical textures of the mesophases were observed with an Olympus BX60 polarizing microscope equipped with a Linkam THMS600 hot stage and a Linkam TMS93 programmable temperature controller. High temperature X-ray diffraction was measured on a STOE Transmission Powder Diffractometer System STADI P, with a high temperature attachment version 0.65.1 (temperature range from room temperature to $\left.1000{ }^{\circ} \mathrm{C}\right)$. Monochromatic $\mathrm{Cu} \mathrm{K} \mathrm{K}_{\alpha 1}$ radiation $(\lambda=1.5406 \AA$ ) was obtained with the aid of a curved germanium primary monochromator. Diffracted X-rays were measured by a linear Position Sensitive Detector (PSD). The sample was placed in a quartz glass capillary (outer diameter $0.3 \mathrm{~mm}$, wall thickness $0.01 \mathrm{~mm}$ ) and spinned during the measurement. In general, data were collected in the range $1<2 \theta<40^{\circ}$.

1,2-Bis(dodecyloxy)benzene. A mixture of catechol (44g, $0.4 \mathrm{~mol})$, 1-bromododecane (192 mL, $0.8 \mathrm{~mol}$ ), $\mathrm{K}_{2} \mathrm{CO}_{3}(111 \mathrm{~g}, 0.8 \mathrm{~mol})$ and $1 \mathrm{~mL}$ of Aliquat 336 (phase transfer catalyst) was heated during 3 hours at $120{ }^{\circ} \mathrm{C}$ under a nitrogen atmosphere. After leaving the mixture too cool to room temperature, $500 \mathrm{~mL}$ of water and $200 \mathrm{~mL}$ of dichloromethane were added. The organic layer was separated and the aqueous layer extracted with 3 x $50 \mathrm{~mL}$ of diethyl ether. The combined organic layers were washed with $200 \mathrm{~mL}$ of a saturated brine solution, dried over anhydrous $\mathrm{MgSO}_{4}$ and concentrated. The residue was recrystallized from acetone. Yield: $70 \%$ (125 g); m.p. $45^{\circ} \mathrm{C}$. MS (EI) m/z: $446\left(\mathrm{M}^{+}\right.$). IR (KBr): 3000-2750 (alkyl); 1500 (aryl); 750 (osubstituted benzene) $\mathrm{cm}^{-1}$. ${ }^{1} \mathrm{H}-\mathrm{NMR} \delta\left(\mathrm{CDCl}_{3}\right): 0.88\left(\mathrm{t}, 6 \mathrm{H}, \mathrm{CH}_{3}\right), 1.26\left(\mathrm{~m}, 36 \mathrm{H}, \mathrm{CH}_{2}\right), 1.81(\mathrm{~m}$, $\left.4 \mathrm{H}, \beta-\mathrm{CH}_{2}\right), 3.99\left(\mathrm{t}, 4 \mathrm{H}, \mathrm{OCH}_{2}\right), 6.88(\mathrm{~s}, 4 \mathrm{H}, \mathrm{Ar})$. Elemental analysis: calcd. for $\mathrm{C}_{30} \mathrm{H}_{54} \mathrm{O}_{2}$ (446.75): C 80.65, H 12.18; found: C 80.32, H $12.08 \%$.

1,2-Dibromo-4,5-bis(dodecyloxy)benzene. A solution of bromine $(16 \mathrm{~mL}, 0.3 \mathrm{~mol})$ in $110 \mathrm{~mL}$ of dichloromethane was slowly added to an ice-cooled solution of 1,2-bis(dodecyloxy)benzene $(67 \mathrm{~g}, 0.15 \mathrm{~mol})$ in $200 \mathrm{~mL}$ of dichloromethane. After addition was complete, the mixture was stirred for another 3 hours, when formation of $\mathrm{HBr}$ gas ceased ( $\mathrm{HBr}$ was trapped by bubbling it through a concentrated aqueous $\mathrm{NaOH}$ solution). The excess of bromine in the solution was destroyed by adding an aqueous $\mathrm{NaHSO}_{3}$ solution. The organic layer was washed with a $\mathrm{NaHCO}_{3}$ solution, and with water. After the organic layer was dried over anhydrous $\mathrm{MgSO}_{4}$, the solvent was evaporated under reduced pressure. The residue was recrystallized from acetone. 
Yield: 94\% (85 g); m.p. $50{ }^{\circ} \mathrm{C}$. MS (EI) m/z: $604\left(\mathrm{M}^{+}\right.$). IR (KBr): 3000-2750 (alkyl); 1500 (aryl); 750 (o-substituted benzene) $\mathrm{cm}^{-1}$. ${ }^{1} \mathrm{H}-\mathrm{NMR} \delta\left(\mathrm{CDCl}_{3}\right): 0.88\left(\mathrm{t}, 6 \mathrm{H}, \mathrm{CH}_{3}\right), 1.26(\mathrm{~m}, 36 \mathrm{H}$, $\left.\mathrm{CH}_{2}\right), 1.81\left(\mathrm{~m}, 4 \mathrm{H}, \beta-\mathrm{CH}_{2}\right), 3.99\left(\mathrm{t}, 4 \mathrm{H}, \mathrm{OCH}_{2}\right), 7.06(\mathrm{~s}, 2 \mathrm{H}, \mathrm{Ar})$. Elemental analysis: calcd. for $\mathrm{C}_{30} \mathrm{H}_{52} \mathrm{Br}_{2} \mathrm{O}_{2}$ (604.54): C 59.60, $\mathrm{H} 8.67$; found: C 59.20, $\mathrm{H} 8.55 \%$.

1,2-Dicyano-4,5-bis(dodecyloxy)benzene. A solution of 1,2-dibromo-4,5-bis(dodecyl)benzene $(55 \mathrm{~g}, 0.094 \mathrm{~mol})$ and $\mathrm{CuCN}(24.2 \mathrm{~g}, 0.27 \mathrm{~mol})$ in $4000 \mathrm{~mL}$ of DMF was heated at reflux during 5 hours under a nitrogen atmosphere. After left to cool to room temperature, the reaction mixture was filtered, and the filtrate was evaporated to dryness. The precipitate on the filter was washed with $600 \mathrm{~mL}$ of dichloromethane. This organic solution was combined with the solid residue, and the resulting solution was stirred during 15 hours with $600 \mathrm{~mL}$ of a concentrated aqueous ammonia solution. The organic layer was washed with water and dried over anhydrous $\mathrm{MgSO}_{4}$. The solvent was evaporated under reduced pressure, and the crude product was purified by column chromatography with $\mathrm{SiO}_{2}$ as the stationary phase and toluene as the eluent. Yield: $94 \%$ (85 g); m.p. $105{ }^{\circ} \mathrm{C}$. MS (EI) m/z: $496\left(\mathrm{M}^{+}\right.$). IR (KBr): 3000-2750 (alkyl); 2250 (CN stretch), 1500 (aryl); 750 (o-substituted benzene) $\mathrm{cm}^{-1} .{ }^{1} \mathrm{H}-\mathrm{NMR} \delta\left(\mathrm{CDCl}_{3}\right): 0.88\left(\mathrm{t}, 6 \mathrm{H}, \mathrm{CH}_{3}\right), 1.26(\mathrm{~m}$, $\left.36 \mathrm{H}, \mathrm{CH}_{2}\right), 1.85\left(\mathrm{~m}, 4 \mathrm{H}, \beta-\mathrm{CH}_{2}\right), 4.05\left(\mathrm{t}, 4 \mathrm{H}, \mathrm{OCH}_{2}\right), 7.11$ (s, 2H, Ar). Elemental analysis: calcd. for $\mathrm{C}_{32} \mathrm{H}_{52} \mathrm{~N}_{2} \mathrm{O}_{2}$ (496.77): C 77.37, $\mathrm{H}$ 10.55, N 5.64; found: C 77.23, $\mathrm{H} \mathrm{10.53,} \mathrm{N} \mathrm{5.51} \mathrm{\% .}$

2,3,9,10,16,17,23,24-Octakis(dodecyloxy)phthalocyanine-zinc(II). A mixture of 1,2-dicyano4,5-bis(dodecyloxy)benzene (1.00 g, $2 \mathrm{mmol}), \mathrm{ZnCl}_{2}(74 \mathrm{mg}, 0.54 \mathrm{mmol}), 5 \mathrm{~mL}$ of 2(dimethylamino)ethanol and 4 drops of 1,8-diazobicyclo[5.4.0]undec-7-ene (DBU) was stirred at reflux temperature during 48 hours under a nitrogen atmosphere. After evaporation to dryness, the green residue was dissolved in few milliliters of chloroform and reprecipitated in $50 \mathrm{~mL}$ of acetone. The precipitate was filtered over a Gooch crucible (porosity 4) and washed with acetone, methanol and ethyl acetate. Further purification was done by chromatography over (neutral) $\mathrm{Al}_{2} \mathrm{O}_{3}$ using $\mathrm{CHCl}_{3}$ as the eluent. After collection and evaporation the compound was recrystallized in ethyl acetate and dried overnight. Yield 46\% (470 mg). MS (MALDI-TOF) $\mathrm{m} / \mathrm{z}$ : 2050.8 (calcd. for $\mathrm{C}_{128} \mathrm{H}_{208} \mathrm{O}_{8} \mathrm{~N}_{8} \mathrm{Zn}$ : 2049.54). IR (KBr): 1610 (arom. C=C), 1275 (Ar-O), 1095 (Ar-O-C). The absence of metal free phthalocyanine was verified by IR-spectroscopy (no N-H absorption bands) and by UV/VIS (no splitting of Q-band).

The precursors 1,2-dicyano-4,5-bis(octyloxy)benzene and 1,2-dicyano-4,5-bis(hexadecyloxy) benzene were obtained by a method similar to that described for 1,2-dicyano-4,5bis(dodecyloxy)benzene. The cobalt(II), nickel(II) and copper(II) complexes were synthesized according to the method described for the zinc(II) complex, using respectively $\mathrm{CoCl}_{2} \cdot 6 \mathrm{H}_{2} \mathrm{O}$ $\mathrm{NiCl}_{2} \cdot 6 \mathrm{H}_{2} \mathrm{O}$ and $\mathrm{CuCl}_{2} \cdot 2 \mathrm{H}_{2} \mathrm{O}$ as the metal salt. The identity of all the phthalocyanine complexes was verified by MALDI-TOF mass spectrometry and their purity was checked by UV/VIS and IR spectroscopy. Although satisfying CHN analysis results were obtained for all the organic precursor compounds, no reproducible $\mathrm{CHN}$ data are available for the metallophthalocyanines. These problems are most likely due to incomplete combustion (even after addition of $\mathrm{V}_{2} \mathrm{O}_{5}$ as combustion catalyst). 


\section{Acknowledgments}

KB thanks the F.W.O.-Flanders (Belgium) for a Postdoctoral Fellowship. JS is indebted to the 'Flemish Institute for the Encouragement of Scientific and Technological Research in the Industry (IWT)' for financial support. Financial support by the F.W.O.-Flanders (G.0243.99) is gratefully acknowledged. MALDI-TOF mass spectra were measured by G. Baggerman (K.U.Leuven). We wish to thank Prof. G. Meyer and Dr. D. Hinz-Hübner (University of Cologne, Germany) for the X-ray measurements.

\section{References}

1. Piechocki, C.; Simon J.; Skoulios, A.; Guillon, D.; Weber, P. J. Am. Chem. Soc. 1982, 104, 5245.

2. McKeown, N. B., in Phthalocyanine Materials: synthesis, structure, function, Cambridge University Press (Cambridge) 1998.

3. Simon, J.; Bassoul, P., Phthalocyanine based Liquid Crystals: Towards Submicronic Devices in: Phthalocyanines, Properties and Applications, eds. C.C. Leznoff en A.B.P. Lever, VCH Weinheim, 1993, Volume 2.

4. Serrano, J. L. (ed.), Metallomesogens (Weinheim: VCH) 1996.

5. Simon, J.; Bassoul, P., Design of Molecular Materials; Supramolecular Engineering (Chichester, Wiley) 2000.

6. Guillon, D.; Skoulios, A.; Piechocki, C.; Simon, J.; Weber, P. Mol. Cryst. Liq. Cryst. 1983, 100, 275.

7. Ukei, K. Acta Cryst. B 1973, 29, 2290.

8. Friedel, M.K.; Hoskins, B.F.; Martin, R.L.; Mason, S.A., J. Chem. Soc. Chem. Comm. 1970, 400.

9. Severs, L.M.; Underhill, A.E.; Edwards, D.; Wight, P.; and Thetford, D. Mol. Cryst. Liq. Cryst. 1993, 234, 235.

10. van der Pol, J. F.; Neeleman E.; Zwikker, J. W.; Nolte, R. J. M.; Drenth, W. Trav. Chim. Pays-Bas 1988, 107, 615.

11. van der Pol, J. F.; Neeleman E.; Zwikker, J. W.; Nolte, R. J. M.; Drenth, W.; Aerts, J.; Visser, R.; Picken, S.J. Liq. Cryst. 1989, 6, 577.

12. Sleven, J.; Binnemans, K.; Görller-Walrand, C. Mater. Sci. Eng. C. 2001, 18, 229.

13. Sleven, J.; Cardinaels, T.; Binnemans, K.; Nelis, D.; Mullens, J.; Hinz-Hübner, D.; Meyer, G. Liq. Cryst. 2002, 29, in press.

14. Sleven, J.; Cardinaels, T.; Binnemans, K.; Guillon, D.; Donnio, B. Liq. Cryst. 2002, 29, 1425 .

15. Ohta, K.; Jacquemin, L.; Sirlin, C.; Bosio, L.; Simon, J. New. J. Chem. 1988, 12, 751. 